\title{
Systems solutions by lactic acid bacteria: from paradigms to practice
}

\author{
Willem M de Vos \\ From 10th Symposium on Lactic Acid Bacterium \\ Egmond aan Zee, the Netherlands. 28 August - 1 September 2011
}

\begin{abstract}
Lactic acid bacteria are among the powerhouses of the food industry, colonize the surfaces of plants and animals, and contribute to our health and well-being. The genomic characterization of LAB has rocketed and presently over 100 complete or nearly complete genomes are available, many of which serve as scientific paradigms. Moreover, functional and comparative metagenomic studies are taking off and provide a wealth of insight in the activity of lactic acid bacteria used in a variety of applications, ranging from starters in complex fermentations to their marketing as probiotics. In this new era of high throughput analysis, biology has become big science. Hence, there is a need to systematically store the generated information, apply this in an intelligent way, and provide modalities for constructing self-learning systems that can be used for future improvements. This review addresses these systems solutions with a state of the art overview of the present paradigms that relate to the use of lactic acid bacteria in industrial applications. Moreover, an outlook is presented of the future developments that include the transition into practice as well as the use of lactic acid bacteria in synthetic biology and other next generation applications.
\end{abstract}

\section{Introduction}

The historic use of bacteria that produce lactic acid and collectively are designated lactic acid bacteria (LAB) is well documented for a variety of food fermentations, some even dating back to the earliest written records. However, less exposed is the impact of LAB in the diet of our far-away ancestors that lived over a million of years ago. There is considerable support for the hypothesis that lactobacilli and other notably plant-related LAB have been consumed in large amounts in neolithic times [1]. This so called paleo-diet may have contained over a million more microbes than our present foods, resulting in a high and continuous load of LAB. In retrospect, this provides an explanation why some LAB have developed intimate interactions with our body and several $\mathrm{LAB}$ are successfully marketed as probiotics $[2,3]$.

Traditionally LAB have been considered to include low $\mathrm{G}+\mathrm{C}$ content Gram-positive bacteria included in the

Correspondence: willem.devos@wur.nl

Laboratory of Microbiology, Wageningen University, The Netherlands, Department of Veterinary Biosciences, and Department of Bacteriology \& Immunology, Helsinki University, Finland

Full list of author information is available at the end of the article phylum Firmicutes that are used as starters for industrial food fermentations, notably those based on raw materials derived from milk, meat and plants. These fermentations together with probiotic products represent a total global market value of over 100 Billion Euro (Table 1) [3,4]. Economically by far the most important products derive from industrial dairy fermentations and include cheese, yoghurt and other fresh dairy produce. These fermentations are initiated by well-known genera of LAB that include Lactobacillus, Lactococcus and Streptococcus. However, the market for probiotic bacteria in foods and supplements is the most rapidly growing segment in the fast moving consumer goods and expected to grow by 10 $\%$ each year [3]. Most of the applied probiotic bacteria are Lactobacillus spp. However, approximately one third are Bifidobacteria, a group of bacteria with a high $\mathrm{G}+\mathrm{C}$ content included in the phylum Actinobacteria that also produce lactic acid but always in combination with acetic acid. Bifidobacteria are almost exclusively found in association with animal hosts [5]. Hence, it is no surprise that some Bifidobacterium strains are also marketed as probiotic bacteria [2,3]. As various reviews on the genomics and metabolism of Bifidobacteria have been reported 
Table 1 Economic value of fermentations including LAB and Bifidobacteria. Data taken from recent market reviews and estimations $[3,4]$

\begin{tabular}{lll}
\hline Product & $\begin{array}{l}\text { Global Market Value } \\
\text { (Euro) }\end{array}$ & Main Bacterial Genera \\
\hline Cheese Products & 55 Billion & $\begin{array}{l}\text { Lactococcus } \\
\text { \&Lactobacillus }\end{array}$ \\
Yoghurt \& Fresh & 25 Billion & $\begin{array}{l}\text { Streptococcus } \\
\text { \&Lactobacillus } \\
\text { Dairy }\end{array}$ \\
Probiotic Products & 20 Billion & $\begin{array}{l}\text { Lactobacillus } \\
\text { \&Bifidobacterium }\end{array}$ \\
\hline
\end{tabular}

recently [5-7], specific attention for this group is not in the remit of this paper that will focus on the true LAB.

At the time that we are celebrating the 30 year anniversary of the LAB symposia with the present LAB10, it is appropriate to reflect and benchmark the position where the science in this area has led us. Even more important is the possibility to look ahead and present some future perspectives in this area. This is done here with a focus on the practical impact of the paradigm bacteria that underpin a multibillion Euro industry (Table 1). Moreover, this is guided by the three major developments that have brought the research on these powerhouses of the probiotic and dairy industry at the level that it has now. The first is the genomic revolution that has been quickly implemented in LAB with the sequence analysis of plamids, bacteriophages, and now genomes or collections of genomes (Fig. 1). The second is the high throughput experimentation that has become available and shown to be of particular use for LAB. The final development relates to the systems and synthetic biology approaches. These systems solutions integrate all aspects of the metabolism, genetics and application of LAB that have been the leading theme of the past LAB symposia leading to the present LAB10.

\section{Paradigm genetic elements - early industrial impact}

An important part of the research on LAB is characterized by a strong focus on molecular biology and genetics. This reflects the attention for this discipline originating with the development of biotechnology. However, another relevant factor contributing to the attention for the genetics of LAB is the large impact of genetic elements, such as plasmids and bacteriophages. It appeared from the pioneering work of Larry L. McKay that lactococci, then known as lactic streptococci, harbor large plasmid complements and code for important functions [8]. Many of these plasmids and bacteriophages have been characterized at the sequence level and deposited in the NCBI database accounting for a large genomic collection in the early nineties (Fig. 1). However, even prior to this time, when deposition was not common, many lactococcal plasmids have been sequenced, starting more than 25 years ago with the $2.2 \mathrm{~kb}$ pSH71 replicon $[9,10]$. Many mobile elements that also include conjugative transposons were found to encode important industrial characteristics such as lactose and citrate metabolism, proteinase, bacteriocin and exopolysaccharide (EPS) production, as well as bacteriophage insensitivity. The early discoveries that originate from a basic characterization of their molecular properties have resulted in a variety of applications and these paradigms are summarized here (Table 2).

Among the most important applications with significant industrial impact has been the stacking of genetic elements in starter cultures that has been exploited to great extent to increase bacteriophage resistance. As the improved strains are obtained via natural conjugation systems, no genetically modified organisms (GMOs) are generated, and hence this has become one of the hallmarks of industrial strain improvement of LAB $[21,22,38]$. The number of bacteriophage insensitivity systems is ever increasing and these continue to generate practically useful strains, specifically for the dairy practice where an enormous load of bacteriophage is encountered. Similarly, conjugative transposons encoding metabolic properties, such as the sucrose-nisin transposon and derivatives have been discovered [24]. These have been exploited for generating nonGMO starter strains that produce nisin and hence reduce contaminating Listeria and other pathogens [39]. Moreover, new genetic elements continue to be discovered by comparative and functional genomics approaches. These include the conjugative maltose transposon detected in a plant-derived strain of Lactococcus lactis and transferable to model strains of Lactococcus lactis[40]. In addition, genetic islands have been discovered and found to encode the production of mucus-binding pili in the probiotic Lactobacillus rhamnosus GG [31]. Finally, a highly important system that protects prokaryotes from invasion by foreign DNA such as bacteriophages and plasmids, is the CRISPR system that has been discovered in Streptococcus thermophilus[32-34]. About half of the bacteria contain this CRISPR system and this also applies to the LAB where, for instance, it is absent in Lactobacillus plantarum and hence it can be considered as a specific genetic element. The CRISP system forms a nucleic acid based immunity system requiring the action of the specific endonuclease activity of the CRISPR-associated Cascade complex that recently has been worked out in detail [41]. The CRISPR sequences are identical to parts of the bacteriophage genomes to which the strains are immune and hence they have significant diagnostic value as they are indicative of the bacteriophage history [34]. Moreover, the CRISPRsystem forms an important basis for the rational production of bacteriophage-insensitive mutants that are essential for successful industrial fermentations. It was observed 


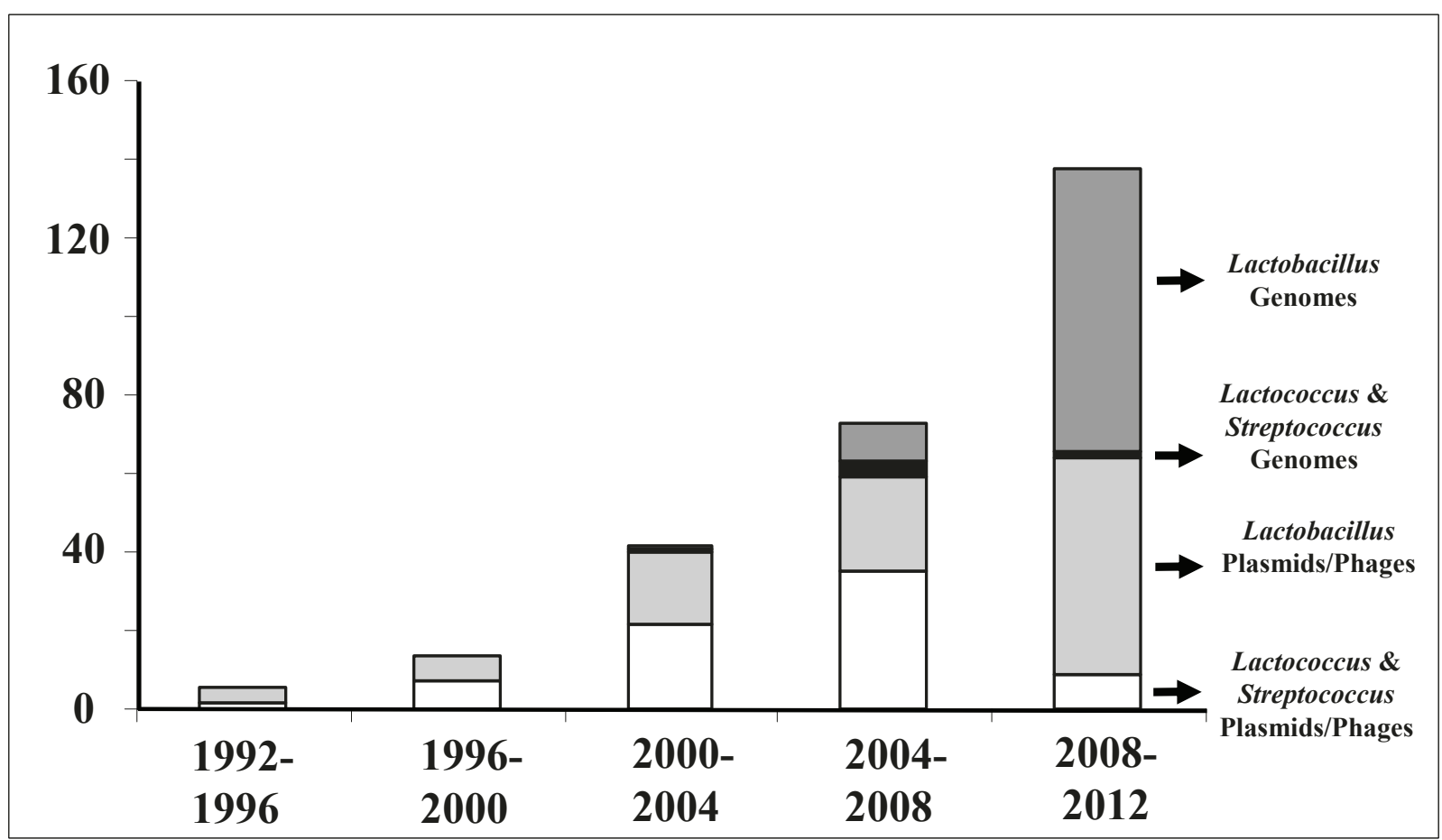

Figure 1 Development of genome sequencing in the last two decades. The number of entries in the NCBI database were scored and summed for the plasmids and bacteriophages [phages] as well as the genomes from Lactobacillus or Lactococcus and Streptrococcus spp. that are considered as LAB.

that the Cascade system can be functionally transferred [42]. This opens avenues for its further exploitation in LAB that do not contain it naturally.

Several of the plasmid replicons such as that from the related plasmids pSH71 and pWV01, have been studied extensively and formed the basis for optimizing hostvector and transformation systems $[10,11,43]$. It is of interest to note that many of the gene cloning, expression and secretion systems developed more than 25 years ago [at the time that lactococci were still known as streptococci], are still in use today in only slightly modified form $[9,11]$. This also holds for food-grade cloning and expression systems that were developed based on extensive molecular characterization of the

Table 2 Paradigms of the mobile and other genetic elements in LAB

\begin{tabular}{|c|c|c|c|}
\hline Function & Paradigm Element [Genes] & Discovery or Exploitations & References \\
\hline Replication & $\mathrm{pW} 01 / \mathrm{pSH} 71[\mathrm{rep} A B]$ & Plasmid Vectors and Copy Number & {$[9-11]$} \\
\hline Lactose Metabolism & pLP712 [lacFEG] & Controlled Expression; Food Grade Markers & {$[12-14]$} \\
\hline High Frequency Conjugation & pLP712 [cluA] & Clumping and High Frequency Conjugal Transfer & {$[15]$} \\
\hline Proteinase Production & pWV05 - pSK112 [prtPM] & Chaperon Function; Flavor Engineering & {$[16-18]$} \\
\hline Citrate Metabolism & $\mathrm{pCT176}[\mathrm{citP}]$ & Citrate Transport; Flavor Engineering & {$[19]$} \\
\hline Bacteriophage Resistance & pTR2030 [abiA-abiZ] & Bacteriophage Resistant Starters & {$[20-22]$} \\
\hline Nisin and Phage Resistance & pNP40 & Bacteriophage Resistance Starters & [23] \\
\hline Sucrose-Nisin Transposon & Tn5276 [sac \&nis operons] & Conjugal Transfer; Antimicrobial Strains; NICE system] & {$[24,26]$} \\
\hline EPS Production & pNZ4000 [eps operon] & EPS Priming Polymerase; Structure Engineering & {$[27]$} \\
\hline Temperate Phage & Bacteriophage $\mathrm{r} 1 \mathrm{t}$ & Temperature Controlled Expression & {$[28-30]$} \\
\hline Mucus Binding & GGISL2 [spaCBA-srtA] & Genomic Island for Mucus Binding Pili & {$[31]$} \\
\hline Phage and Plasmid Resistance & CRISPR-cas operon & Bacteriophage \& Plasmid Immunity System & {$[32-34]$} \\
\hline Production of SLP & SLP & Phase Variation and SLP Induced DC SIGN signalling & {$[35-37]$} \\
\hline
\end{tabular}

The canonical functions of the elements are provided with its genetic designation and, if appropriate, the relevant genes. Moreover, the potential impact of elements is indicated with key references. The elements include plasmids, transposons, genomic islands, gene cassettes or other discrete genomic sequences. NICE: Nisin Inducible Controlled Expression, SLP; Surface Layer Protein. 
lactococcal lactose metabolism [12,14]. Moreover, detailed analysis of the nisin biosynthetic pathway led to the discovery of peptide-mediated communication modules [25]. These formed the basis for the Nisin Induced Controlled Expression (NICE) systems that are used worldwide for controlled gene expression $[26,44]$. The utility of this system was demonstrated in dozens of studies [45]. An important spin off was the development of controlled lysis in cheese starters that may contribute to accelerated cheese ripening [46]. Similarly, the genomic characterization of the first complete lactococcal bacteriophage resulted in the development of a controlled expression system based on its regulatory circuit $[29,30]$.

\section{Paradigm strains of LAB - from genetic models to application}

Given the interest and developments in the LAB genetics it is no surprise that genomics approaches were embraced in the early days (Fig. 1). As complete genome sequencing was relative slow and notably expensive, there was a strong focus on a limited set of model strains that have developed into paradigms for further applications. The early LAB research was dominated by attention for Lactococcus lactis due its importance as starter culture for industrial dairy fermentations (Table 1). As the dairy lactococci contain a large plasmid complement, plasmid-free strains were developed and two elegantly constructed strains MG1363 and IL1403 were developed in the early 80's $[47,48]$. In retrospect these strains served as models for Lactococcus lactis subsp. cremoris (MG1363) and lactis (IL1403). A draft genome of the 2.4 Mb Lactococcus lactis IL1403 was generated ten years ago [49] and finalized [50], whereas that of the strain MG1363 with a slightly larger size of $2.5 \mathrm{Mb}$ was reported somewhat later [51]. As MG1363 is by far the most widely used lactococcal model strain, its genome was recently resequenced, resulting in the correction of multiple mistakes [52]. The latter study also provided the complete genome sequence of the derivative strain NZ9800, carrying Tn5276 and a 4-bp deletion in the nisA gene, which is used as a host for the NICE system [44]. These paradigm strains of Lactococcus lactis form the basis for hundreds of genetic and metabolic studies that have been carried out today. Remarkably, new series of discoveries continue to be made as has recently been shown by the presence of a pellicle polysaccharide that covers the surface of strain MG1363 that [53].

The notion that Lactobacilli are of great importance specifically for probiotic culture developments has greatly stimulated their genomic characterization. The genome of Lactobacillus plantarum was the first to be completed and found to be among the largest genomes to date with a size of 3.3 $\mathrm{Mb}$ [54]. This organism was selected as it was a human isolate, was able to grow fast on a variety of sugars, and was accessible to high efficiency genetic transformation. Moreover, it had been found to efficiently survive the intestinal tract passage making it an ideal paradigm probiotic or delivery strain [55]. The genetic blue print of Lactobacillus plantarum served as a basis for rapid insight into its use in food fermentations as well as a probiotic microbe and sparkled a wave of research interest generating over 100 publications that are related to its genome. The hallmark discoveries related to its genome include the finding that the degree of alanylation of its lipotechoic acids (LTAs) affects its immune response [56], the notion that its survival in the human and murine host induces over 500 genes that are not expressed in laboratory media [57], and the observation that its exposure in the upper intestinal tract of human induces a marked anti-inflammatory immune response [58]. Moreover, Lactobacillus plantarum has served to construct the first genome-based metabolic model generated for LAB [59] and sparkled may other metabolic, genetic and immunological studies that have recently been reviewed [60-62].

While Lactococcus lactis and Lactobacillus plantarum have developed into true paradigm strains, many other LAB are attractive candidates for model studies as they have unique features and have large economic impact (Table 1). A selection of these are summarized here with attention for the genomic characterization and impact in research and application (Table 3). Many of them are highly transformable and this has promoted their use as genetic model systems. It is of interest to note that there is an inverse correlation between the presence of the CRISPR - cas system [34] and transformability and in retrospect it explains the relatively late discovery of this important immunity system in LAB (Table 3). Important probiotic paradigms are Lactobacillus acidophilus NCFM and Lactobacillus rhamnosus GG, both of which are worldwide used as probiotic strains [2]. Their genomes have sparked the discovery of probiotic mechanisms, some of which are located on special genetic elements [Table 2]. These include the SLP-element that is affected by induced phase variation in Lactobacillus acidophilus NCFM and produces SlpA that mediates signaling to the DC-SIGN receptor of dendritic cells [37]. In addition, the genomic island ISSL1 in Lactobacillus rhamnosus GG was found to encode the production of pili, protruding filaments of around a micron in length that so far only have been discovered in Gram-positive pathogens [31]. These pili were decorated with the pilus protein SpaC that bound to human mucus, providing a molecular basis for competitive exclusion with other mucus-binding pathogens [[31], and unpublished observations]. It was observed earlier that reducing the degree of alanylation, and hence the positive charge, of LTA in Lactobacillus plantarum affected its immune stimulation and reduced colitis in a murine model [56]. Similarly, it was recently reported that the complete removal of LTAs acids in 
Table 3 Paradigm strains of LAB. A listing of the most relevant LAB strains, their genome size and year of publication is provided. Moreover, the presence of CRISPR sequences is given with a summary of the reported transformation frequency, varying from very high, high, medium to low, representing $10^{6}-10^{8}, 10^{4}-10^{6}, 10^{2}-10^{4}, 10^{0}-10^{2}$ transformants per ug of DNA, respectively. ND, indicates not determined

\begin{tabular}{|c|c|c|c|c|c|}
\hline Paradigms Strains & Genome Size & Publication Year & Transformation & CRISPR & References \\
\hline Lactococcus lactis IL 1403 & $2.4 \mathrm{Mb}$ & 2001 & very high & none & {$[50]$} \\
\hline Lactococcus lactis MG1361 & $2.5 \mathrm{Mb}$ & 2007 & very high & none & {$[51]$} \\
\hline Lactobacillus plantarum WCFS1 & $3.3 \mathrm{Mb}$ & 2003 & very high & none & {$[54]$} \\
\hline Lactobacillus acidophilus NCFM & $2.0 \mathrm{Mb}$ & 2005 & high & none & {$[63]$} \\
\hline Lactobacillus rhamnosus GG & $3.3 \mathrm{Mb}$ & 2009 & medium & yes & {$[31]$} \\
\hline Lactobacillus salivarius UCC118 & $2.0 \mathrm{Mb}$ & 2006 & medium & yes & {$[64]$} \\
\hline Lactobacillus bulgaricus & $1.9 \mathrm{Mb}$ & 2006 & low & yes & [65] \\
\hline Streptococcus thermophilus & $2.0 \mathrm{Mb}$ & 2004 & medium & yes & {$[66]$} \\
\hline
\end{tabular}

Lactobacillus acidophilus induced its anti-inflammatory signaling to dendritic cells and also reduced colitis in a murine model [67]. These observations provide a molecular explanation for previous findings for the in vitro interaction between lactobacilli and the immune system. This was recently confirmed in healthy volunteers where a specific immune response of the upper intestinal tract was observed following exposure to cells of Lactobacillus plantarum [58] and other probiotic strains, including Lactobacillus rhamnosus GG and a Lactobacillus acidophilus strain [68]. Another seminal finding derived from the genomic characterization of the probiotic strain Lactobacillus salivarius UCC118 and the detection of the coding capacity of a broad-spectrum class II bacteriocin that inactivated Listeria monocytogenes [66] Wild-type Lactobacillus salivarius UCC118 but not its bacteriocinnegative mutant was found to protect mice from the killing effect of challenges of Listeria monocytogenes, illustrating another probiotic mechanisms [69].

With increasing technological developments and reduction of sequencing costs, more genomes were sequenced in the last decade, including those of the yoghurt strains Lactobacillus bulgaricus[64] and Streptococcus thermophilus [65]. An important development was the comparative analysis of nine LAB genomes in a single study, covering wide application areas varying from dairy fermentations to wine production [70]. Presently over 100 genomes of LAB are deposited in public databases (Fig. 1). The majority of these genomes have not been closed as this is notably difficult because of the presence of multiple repetitive sequences, such as Insertion Sequences (ISs). However, as a framework of around 25 completely closed LAB genomes is presently available, comparative and other detailed analyses offer new leads for functional studies as discussed below.

\section{Comparative, pan and meta-genomics developments}

In silico comparative genomics has been applied ever since the first complete genomes of the same genus were reported and included those of Lactobacillus plantarum and Lactobacillus johnsonii[71]. However, these genomes differ in size by about $1 \mathrm{Mb}$ and limited conservation was observed [72]. On a larger scale, comparative genomics was applied to explain the origin of $\mathrm{LAB}$ based on a set of a dozen different LAB genomes [70]. An evolutionary tree of $\mathrm{LAB}$ could be generated that explained the present LAB genomes by a series of multiple gene losses and acquisitions. This important concept also indicated that LAB and Bacillus subtilis shared a common ancestor, providing a teleological explanation for the success of many genetic tools that have been developed for Bacillus systems and work efficiently in LAB and vice versa. The recent observation that Streptococcus thermophilus and possibly other LAB may become competent and hence are naturally transformable provides another practically important example [73]. Natural transformation in conjunction with other mutation selection systems would provide an important tool to expand the genetic potential of LAB without them being labeled as GMO.

Most of the LAB genomes contain around 2000-3000 genes. The question arises how different these genes are and whether a core genome can be found. Comparative analysis of 20 completely sequenced Lactobacillus genomes showed the pan genome to contain approximately 14000 genes and indicated the presence of a core genome of 383 orthologous genes [74]. These and other comparative studies confirmed the fact that about one third of the pan genome can not be accurately annotated and that there exists series of wrongly or poorly annotated genes. In silico comparative genomics approaches can address those and together with experimental analyses lead to improved annotations and discovery of new functions. The first of these were performed by comparative genome hybridization using a microarray of Lactobacillus plantarum WCFS1 that was tested with DNA of a dozen of related strains from different habitats [75]. The results indicated the presence of specific genomic regions, called 
life-style islands that were already predicted from the genome with unusual $\mathrm{G}+\mathrm{C}$ content and varied between the different strains [54]. Moreover, gene-trait matching was performed and this led to the discovery of a mannose-binding protein encoding gene that is present in probiotic strains of Lactobacillus plantarum and may contribute to competitive exclusion with pathogenic Escherichia coli strains that are known to bind to mannose [76]. Various other comparative genomic studies capitalized on large strain collections and advanced bioinformatic tools developed to allow for rapid genetrait matching [77]. Recently, this led to the assignment of a series of candidate genes involved in immunological signaling [78]. The advantage of comparative genome hybridization is that use is made of the natural biodiversity of LAB and rapid molecular insight is generated. From an applied perspective this is highly desired as it is a non-GMO approach. However, as all comparisons are realized by using an array of a single strain, no insight in any new coding sequences is generated and this can only be realized by sequence analysis and in silico comparisons.

Advanced comparative genomics and metagenomics approaches can nowadays be realized by deep sequence analysis using Next Generation Technology (NGT) sequencing approaches. The first LAB genome that was completed using NGT sequencing was that of Lactobacillus rhamnosus GG and all following ones have been based on some form of NGT sequencing. In addition, deep resequencing has been realized that generated the genome sequence of the well-known strain NZ9000 used as host for the NICE system [44] and this also allowed for correcting sequence errors in the genome of its parent MG1363 [52]. Moreover, draft genome sequences that are almost full length have been generated as is illustrated by the genomic sequencing of a dozen of Lactobacillus strains as part of the Human Microbiome Project [79]. The use of NGT sequencing approaches explains the rapid boost in the number of LAB genomes deposited in public databases in recent years [Fig. 1]. To exemplify the rapid analysis, we determined recently draft genomic sequences of approximately 100 strains of Lactobacillus rhamnosus-like strains obtained from food, clinical and other environmental samples using NGT approaches [WMdV, unpublished observations].

Next to advanced comparative genomics also metagenomic approaches are being applied using NGT sequencing and these are specifically suitable for the analysis of mixed cultures. The practical importance of mixed strain starters is enormous as cultures of LAB consisting of multiple strains of undefined composition are widely used in the dairy and other food industries. In many cases these mixed strain starters are used intentionally to increase the diversity, and hence resilience and robustness. In other cases, mixed cultures are used unintentionally and relate to the heterogeneity that originates when strains of LAB are repeatedly subcultured [80]. Many mixed cultures also contain bacteriophages that contribute to the equilibrium between the strains, as has been illustrated for the phagecarrying situation [81]. Such mixed starter cultures can be seen as developing ecosystems. Hence, the application of NGT sequencing approaches to describe its collective metagenome will be instrumental in understanding the behavior of these mixed cultures and explaining as well as predicting their success in industrial fermentations.

\section{High throughput developments - functional analysis and screening}

One of the great achievements of the omics revolution is the development of high throughput functional genomics approaches. Notably transcriptomics studies have been instrumental in analyzing the response of LAB to different environments and over 100 papers have been published addressing a variety of stresses, growth conditions and culturing regimens. Among the most important practical discoveries was the finding that Lactococcus lactis and other $\mathrm{LAB}$, when provided with the appropriate cofactors, such as heme, could use alternative electron acceptors and hence respire rather than ferment [82]. Following the first description of the use of molecular oxygen by Lactococcus lactis MG1363 [83], a variety of studies have followed that have been reviewed recently [84]. Transcriptional studies allowed to identify the genes involved in the use of molecular oxygen that resulted in a wide range of applications, notably faster growth and higher yield of starter cultures [85]. Biochemical studies confirmed that indeed a proton motive force was generated during respiration illustrating the link between transcriptional and functional studies [86]. Moreover, some LAB also were found to use nitrate as terminal electron acceptor, expanding further the possibilities beyond fermentation [87].

Analysis of the transcriptional response is a powerful tool to study fast responses. The analysis of the response to acid stress was the first microarray study reported and related to Lactobacillus plantarum[88]. Subsequently, a large set of hundreds of transcriptional responses have been collected that have been systematically addressed by advanced correlation analysis using newly developed tools [89]. This helped to find a series of supergenomic networks and provided further insight in global regulation systems as recently reported [89]. Moreover, the use of metabolic maps based on the genome-based modeling [59] permitted rapid display and analysis of the expressed genes and in such a way it was found that during aerobic growth of Lactobacillus plantarum, carbon dioxide was required to allow rapid and uninterrupted growth [90].

Another important observation made by using a community transcriptomics approach was the finding that 
the human isolate Lactobacillus plantarum expressed a completely different set of genes in the intestine as compared to growth in laboratory media [57]. This partly explained the large coding capacity of over 3000 genes of this human isolate. Remarkably, a highly comparable expression profile in mice and human was generated, indicating similarities in the intestinal adaptation [57]. Due to the high signal to noise ratio of the microarrays, this analysis could be performed in the complex intestinal ecosystem where LAB represent a fraction of the total number of cells. More advanced metatranscriptomics studies that also capitalize on this property provided by microarrays aim to analyze the transcriptional response in complex food ecosystems. This requires microarrays of multiple strains and the feasibility can be exemplified with the consortium of Lactobacillus bulgaricus and Streptococcus thermophilus that is involved in yoghurt fermentation [91]. Parallel global transcriptome analysis of the consortium during growth in milk provided evidence for the involvement of specific compounds and metabolic pathways in the interactions between the two strains $[91,92]$. This is one of the few studies that is performed in an industrial environment and the generated insight may be extrapolated to design stable interactions of other consortia of interacting strains, including probiotics.

It is known from earlier studies that characteristic LAB communities are developing in fermented foods such as cheese [93]. Microarrays representing multiple LAB genomes have been used to determine the response during these successions. Insight in the biodiversity and activity was generated for the fermentation of kimchi, a traditional Korean vegetable product, described to contain various health-promoting factors [94]. Similar approaches were recently applied to complex and uncontrolled sour dough fermentations [95]. These examples all relate to fermentations of plant-derived products and it may be expected that use of these approaches will also be instrumental in analyzing the events in industrial dairy fermentations with complex cultures. Presently, NGT sequencing is being applied to determine global transcriptional responses and this holds great potential as the sequence depth is increasing steadily [96]. These approaches are specifically useful to address small RNAs and their processing, possibly noncoding regions, and $\mathrm{LAB}$ communities that have not yet been characterized completely.

Proteomics studies have been instrumental in identifying adaptations that take place over a longer time frame than transcriptomics responses. In a recent systematic study the proteomic and transcriptional responses of the probiotic Lactobacillus rhamnosus GG to bile acid were compared [97]. Both approaches were complementary to each other and pointed towards the reduction in EPS production following exposure to bile acid, suggestion that in the intestinal tract cell-envelope located proteins, such as anchored by the action of sortases, are exposed to the extracellular environment. This provided the basis for new probiotic mechanisms to be analyzed Lactobacillus rhamnosus GG, such as the exposure of the mucus binding protein or the effect of pili in reducing the IL-8 stimulation by lipotechoic acids in human enterocytes that both are more pronounced in EPS-deficient cells [98].

While analysis of relevant metabolites is standard physiological practice, global metabolomics studies have not been reported frequently for $\mathrm{LAB}$, which may be explained by the complex set of biochemical instruments needed for high throughput metabolic analyses. However, a recent comparative metabolomics and transcriptomics analysis of folate-overproducing Lactobacillus plantarum cells was reported to explain its reducing effect on the growth rate [99] . Remarkably, only little effect on the transcriptome and metabolome was observed but the great impact on the growth rate was explained by the gratuitous production of large amounts of folate-related transcripts and proteins.

The usefulness of transcriptomics, proteomics and metabolomics studies depend largely on the stability of the detected molecules. This is not the case with systems that can operate along all time scales and can be detected infinitely as they concern permanent genetic changes. This holds for the in vitro expression technology (IVET) approaches and variations thereof. These are high throughput systems that capitalize on upregulation of gene expression and need efficient transformation systems or intermediary hosts. The first IVET studies in LAB were performed in Lactobacillus plantarum and revealed genes that were upregulated in the murine host [100]. These pioneering studies required the optimization of tools that were later used in IVET studies addressing the response of Lactococcus lactis cultures in the cheese production process. This is a highly relevant approach and this study revealed a series of genes involved in the cheese maturation process [101]. A great variety of efforts focusing on reducing cheese maturation times have been reported, the most advanced being the use of cell density induced lysis of lactococcal cells [46]. However, there is a great need to extend beyond that knowledge and develop systems that are based on the natural induced genes as have now been exposed using the IVET approach.

In general, omics and the other described high throughput approaches generate leads that form the basis for functional genomics approaches. The throughput of these functional studies is often a bottleneck but has been greatly improved by efficient transformation and expression platforms (see above) as well as systems for generating rapidly multiple mutations in a single strain. An efficient cre-lox system for obtaining such multiple mutants in an efficient and successive way have been 
described for Lactobacillus plantarum that may be considered as self-cloning [102]. On the practical side also high throughput developments have been reported and an ingenious system of small cheeses has been designed and used [103]. Finally, a variety of in vitro systems that may predict practical conditions have been reported, such as the use of non-growing cells of Lactococcus lactis strains for the rapid analysis of flavor production [104].

To avoid all GMO related issues, the best optimization of industrial LAB is to generate mutants. While the use of advanced genetic systems, such as mutator strains, has been described [105], natural means of creating diversity are also feasible and may be sufficiently frequent to generate variation that subsequently can be selected. This has been shown for the adaptive evolution of Lactococcus lactis for over 1000 generations that revealed the mobility and subsequent mutation by IS elements [106]. It is well known that IS elements are a powerful source of generating variation as has been illustrated for the construction of lactose-deficient mutants to prevent post-fermentation acidification in Lactobacillus bulgaricus[107]. Another dimension has been generated by all kinds of high throughput equipment and is supported by whole genome NGT resequencing to provide insight in the nature of the generated mutations. This has been tested in the adaptive evolution of yoghurt strains that had not previously been grown together in a consortium. It was found that more than 1000 generations of growth resulted in stable consortia of naïve strains of Lactobacillus bulgaricus and Streptococcus thermophilus that even outperformed industrial consortia for growth rate [92]. Whole genome re-sequencing detected multiple mutations in both species that affected metabolic pathways relating to their interdependence. These results illustrate the need for an advanced understanding of the metabolic network relations that can be exploited to generate stable consortia of LAB consisting of fermentative or probiotic strains.

\section{Systems and synthetic biology - integrating metabolism, genetics \& application}

To capture the full potential of the omics and other high throughput development, a systems biology approach is essential [108]. Basically, this allows incorporating experimental data into an intellectual framework of a model and hence integrate these into a hypothesis generating system. In the full circle of the systems biology, the generated hypothesis can be tested experimentally, optimizing and extending the models. The power of this approach can be illustrated by examples of the advances made in Lactobacillus plantarum as reviewed recently [60]. Based on the Lactobacillus plantarum genome, a metabolic model was created that described very well the growth and product formation when grown in minimal media on glucose [59]. What the flux balance analysis model also predicted was that Lactobacillus plantarum strain not only should grow efficiently on hexose sugars but also on glycerol, a C3 compound. However, the wild-type strain showed only a very low growth rate on glycerol, indicating the presence of an unexpected bottleneck. By adaptive evolution supported by efficient growth using oxygen as electron acceptor, a derivative strain of Lactobacillus plantarum was obtained that completely converted glycerol into mainly lactic acid as predicted by the genome-based model [109]. In this systems biology approach, the experimental data provided further insight as genomic resequencing of the resultant strain showed promoter mutations and relieve of catabolite repression of the glycerol operon [E.J. Smid, personal communication]. The inability to predict this bottleneck among others results from the absence of hierarchal control data in the metabolic model and their incorporation would provide the next level of sophistication.

It is evident that systems biology approaches capitalize on genomic information, genome based modeling and high throughput experimentation. As it aims to generate productive outcomes, as such it integrates genetics, metabolism and applications. Moreover, systems biology can capture previous knowledge and this even increases its power [108]. Hence, the paradigm LAB are ideal organisms to further exploit using systems biology approaches. Notably for Lactococcus lactis a large body of information has been collected, including a variety of kinetic, static and genome-based models that have been reviewed $[109,110]$. However, new and refined models are continuously emerging testifying for the interest in the systems biology approach and this paradigm LAB strain [112-114]. Moreover, a wealth of metabolic data is available for Lactococcus lactis MG1363 as it has been used in a multitude of metabolic engineering experiments [115]. Many of these have been highly successful and these are summarized here since under optimal conditions the flux distribution reaches the theoretical maximum (Table 4). These extreme fluxes are highly unusual and affirm the usefulness of Lactococcus lactis as a host for metabolic engineering in which growth and production can be uncoupled [115]. Various factors may contribute to this, including its simple metabolism, limited redundancy and few high level control systems in its small genome. Its relative simplicity was confirmed by comparative modeling studies where genome-based models and transcriptional responses of Lactococus lactis, Lactobacillus plantarum and Streptococus thermophilus were compared [119]. A last level of sophistication in the modeling approach is the construction of models for mixed cultures. This has been realized for the yoghurt consortium consisting of Streptococcus thermophilus and Lactobacillus bulgaricus and provided important support for the explanation of experimental data [92]. Further modeling of more complex consortia of LAB such as in mixed 
Table 4 Selected metabolic engineering studies with Lactococcus lactis MG1363. The new product, its properties and the efficiency of the flux redistribution from glucose

\begin{tabular}{llll}
\hline Product & Functional Properties & Flux & Reference \\
\hline Alanine & Flavor, L-Amino Acid & $>99$ & {$[116]$} \\
$\alpha$-Acetolactate & Flavor, Precursor & $\sim 70$ & {$[117]$} \\
Aceetaldehyde & Flavor, Conservation & $\sim 50$ & {$[118]$} \\
\hline
\end{tabular}

cultures is also feasible and bottom-up as well as topdown approaches to realize this have been recently reviewed [120].

The unusual success of metabolic engineering approaches in Lactococcus lactis [Table 4] together with its high transformation efficiency [Table 2] indicates that this and possibly other LAB are promising candidates for synthetic biology applications. Synthetic DNA was rapidly incorporated in the genetic engineering of LAB and was already 20 years ago used to optimize constructs from Lactococcus lactis expression [121]. In addition, some of the first synthetic promoters were designed for Lactococcus lactis[122]. However, the present developments in synthetic biology not only allow gene fragments, cassettes or operons to be synthesized but even complete genomes [123]. While there are many bottlenecks, varying from modeling multiple gene functions to booting up new genomes, synthetic biology is the ultimate engineering approach that capitalizes upon a real biological understanding. By exploiting designed DNA up to the size of a complete genome, synthetic biology builds upon the systems biology approaches that have been discussed above.

What synthetic biology approaches could be applied to $\mathrm{LAB}$ ? One avenue is to build upon functions that are present and can be optimized, given the profound knowledge of their biology. This can include the production of high value ingredients such as vitamin B12 produced by Lactobacillus reuteri[124], specific flavors from amino acids as synthesized by Lactococcus lactis or Streptococcus thermophilus[119], or the production of plant-stimulating compounds that can be produced by Lactobacillus plantarum at zero-growth conditions [125]. Similarly, one can think of new anti-infectives based on the large potential of LAB in the production of bacteriocins or lantibiotics, such as nisin [127]. However, these are all products that are rather traditional. More exciting are new products or strains. One possibility is to generate biobricks of probiotic gene functions [[128]; Table 2] that can be incorporated in different hosts and, in varying combinations, tested in high throughput systems for functionality. Similarly, new LAB vaccine strains could be developed where large synthetic DNA fragments are employed. Significant developments have emerged since the first description of lactoccci as oral vaccines $[128,62]$ and specific helper functions that boost the antigenic response have recently been discovered [129]. A final option is to further capitalize on the physiological strengths of LAB. These include their high stress resistance, tolerance to low $\mathrm{pH}$, and uncoupling of growth and production. This can be linked to high growth rates, sometimes at elevated temperatures, and the use of both hexoses and $\mathrm{C} 5$ sugars, while redox balancing can be realized in several ways by respiration $[82,84]$ or the use of water-forming NADH oxidases as demonstrated previously [130]. There are great opportunities, including the production of organic acids other than lactic acid, such as succinic acid, malic acid or propionic acid. Moreover, many LAB have a high level of alcohol tolerance and are even observed as contaminants of commercial alcohol production [131]. Hence, the possibilities of producing butanol, isobutanol or higher alcohols can be considered and several engineering efforts towards generating these products have already been reported [132,133]. However, in order to be competitive with present white biotechnology production systems, the LAB hosts should be optimized for prototrophic growth on simple media obviating the need for yeast extract or other additions. With the present metabolic models in combination with synthetic biology approaches this should be feasible and then we would be entering into a new era where exciting new developments are to be expected.

\section{Conclusions}

The genomic characterization of LAB has rocketed and presently over 25 complete and 100 or so nearly complete genomes are available. Many of these derive from strains that serve as scientific paradigms and have reached the market place as the industrial use of LAB is worth over a 100 Billion Euro per year. Several paradigm $L A B$ have been presented here with their most salient features that include genome based modeling as well as systems and synthetic biology approaches. The field of LAB is developing really rapidly and an impressive set of discoveries have been made that had not been anticipated ten years ago [134]. When considering the large amount of knowledge available, the logic step is to further improve existing products and start developing NGT products for food, pharma and white biotechnology. It is an expectation and desire that this review contributes to these exciting new developments by inspiring new scientific talents to do so.

List of abbreviations used

LAB: Lactic Acid Bacteria; GMO: Genetically Modified Organism; IVET: In Vitro Expression Technology; NGT: Next Generation Technology; NICE: Nisin Induced Controlled Expression; SLP: Surface Layer Protein; LTA: Lipotechoic Acid.

This article has been published as part of Microbial Cell Factories Volume 10 Supplement 1, 2011: Proceedings of the 10th Symposium on Lactic Acid 
Bacterium. The full contents of the supplement are available online at http:// www.microbialcellfactories.com/supplements/10/S1.

\section{Acknowledgements}

I am grateful to my collaborators of the past and present who inspired me by their enthusiasm and work that I tried to highlight in the references - I apologize for any omissions due to space limitations or time constraints. This work was partially funded by the unlimited and personal Spinoza Award of the Netherlands Organization for Scientific Research (now), an Advanced Grant of the European Research Council (ERC) and the Academy Professorship of the Finnish Academy of Sciences (AKA).

\section{Competing interests}

The author declares that he has no competing interests.

Published: 30 August 2011

\section{References}

1. Rook GAW: 99th Dahlem Conference on Infection, Inflammation and Chronic Inflammatory Disorders: Darwinian medicine and the 'hygiene' or 'old friends' hypothesis. Clin Exp Immunol 2010, 160:70-79.

2. Saxelin M, Tynkkynen S, Matilla-Sandholm T, De Vos WM: Probiotic and other functional microbes: from markets to mechanisms. Curr Opin Biotechnol 2005, 16:204-211.

3. Global Probiotics Market. Market \& Market 2010, 1-234.

4. OECD-FAO Agricultural Outlook 2011-2019. Highlights OECD; 2010, 1-84.

5. Vaughan EE, Heilig GHJ, Ben-Amor K, De Vos WM: Diversity, vitality and activities of intestinal lactic acid bacteria and bifidobacteria assessed by molecular approaches. FEMS Microbiol Rev 2005, 29:477-490.

6. Bottacini F, Medini D, Pavesi A, Turroni F, Foroni E, Riley D, Giubellini V, Tettelin $\mathrm{H}$, van Sinderen D, Ventura M: Comparative genomics of the genus Bifidobacterium. Microbiology 2010, 156:3243-54.

7. Cronin M, Ventura M, Fitzgerald GF, van Sinderen D: Progress in genomics, metabolism and biotechnology of bifidobacteria. Int J Food Microbiol 2011.

8. McKay LL: Functional properties of plasmids in lactic streptococci. Ant Leeuwenh 1983, 49:259-74.

9. De Vos WM, Simons AFM: Method for preparing proteins using transformed lactic acid bacteria. European Patent 02287261986

10. De Vos WM: Gene cloning and expression in lactic streptococci. FEMS Microbiol. Rev 1987, 46:281-295.

11. Kok J, van der Vossen JM, Venema G: Construction of plasmid cloning vectors for lactic streptococci which also replicate in Bacillus subtilis and Escherichia coli. Appl Environ Microbiol 1984, 48:726-731.

12. De Vos WM, Boerrigter I, van Rooyen RJ, Reiche B, Hengstenberg W: Characterization of the lactose-specific enzymes of the phosphotransferase system in Lactococcus lactis. J Biol Chem 1990, 265:22554-60.

13. van Rooijen RJ, de Vos WM: Molecular cloning, transcriptional analysis, and nucleotide sequence of $l a c R$, a gene encoding the repressor of the lactose phosphotransferase system of Lactococcus lactis. J Biol Chem 1990, 265:18499-503.

14. Platteeuw C, van Alen-Boerrigter I, van Schalkwijk S, de Vos WM: Foodgrade cloning and expression system for Lactococcus lactis. Appl Environ Microbiol 1996, 62:1008-13.

15. Gasson MJ: In vivo genetic systems in lactic acid bacteria. FEMS Microbiol Lett 1990, 87:43-60.

16. Haandrikman AJ, Kok J, Laan H, Soemitro S, Ledeboer AM, Konings WN, Venema G: Identification of a gene required for maturation of an extracellular lactococcal serine proteinase. J Bacteriol 1989, 171:2789-2794.

17. Vos P, Van Asseldonk M, Van Jeveren F, Siezen R, Simons G, De Vos WM: A maturation protein is essential for production of active forms of Lactococcus lactis SK11 serine proteinase located in or secreted from the cell envelope. J Bacterio/ 1989, 171:2795-2802.

18. Vos P, Boerrigter IJ, Buist G, Haandrikman AJ, Nijhuis M, de Reuver MB, Siezen RJ, Venema G, de Vos WM, Kok J: Engineering of the Lactococcus lactis serine proteinase by construction of hybrid enzymes. Protein Eng 1991, 4(4):479-84.

19. David S, van der Rest ME, Driessen AJ, Simons G, De Vos WM: Nucleotide sequence and expression in Escherichia coli of the Lactococcus lactis citrate permease gene. J Bacteriol 1990, 172:5789-94.
20. Dinsmore PK, Klaenhammer TR: Bacteriophage resistance in Lactococcus. Mol Biotechnol 1995, 4:297-314.

21. Sturino JM, Klaenhammer TR: Engineered bacteriophage-defence systems in bioprocessing. Nat Rev Microbiol 2006, 4:395-404.

22. Durmaz E, Klaenhammer TR: Abortive phage resistance mechanism AbiZ speeds the lysis clock to cause premature lysis of phage-infected Lactococcus lactis. J Bacteriol 2007, 189:1417-25.

23. O'Driscoll J, Glynn F, Fitzgerald GF, van Sinderen D: Sequence analysis of the lactococcal plasmid pNP40: a mobile replicon for coping with environmental hazards. J Bacteriol 2006, 188:6629-39.

24. Rauch PJ, De Vos WM: Characterization of the novel nisin-sucrose conjugative transposon Tn5276 and its insertion in Lactococcus lactis. J Bacteriol 1992, 174:1280-7.

25. Kuipers OP, Beerthuyzen MM, de Ruyter PG, Luesink EJ, de Vos WM: Autoregulation of nisin biosynthesis in Lactococcus lactis by signal transduction. J Biol Chem 1995, 270:27299-304.

26. de Ruyter PG, Kuipers OP, de Vos WM: Controlled gene expression systems for Lactococcus lactis with the food-grade inducer nisin. App/ Environ Microbiol 1996, 62:3662-7.

27. van Kranenburg R, Marugg JD, van Swam II, Willem NJ, de Vos WM: Molecular characterization of the plasmid-encoded eps gene cluster essential for exopolysaccharide biosynthesis in Lactococcus lactis. Mol Microbiol 1997, 24(2):387-97.

28. Van Sinderen D, Karsens $H$, Kok J, Terpstra P, Ruiters MHJ, Venema G, Nauta A: Sequence analysis and molecular characterization of the temperate lactococcal bacteriophage r1t. Mol Microbiol 1996, 19:1343-1355.

29. Nauta A, van Sinderen D, Karsens H, Smit E, Venema G, Kok J: Inducible gene expression mediated by a repressor-operator system isolated from Lactococcus lactis bacteriophage r1t. Mol Microbiol 1996, 19:1331-41.

30. Nauta A, van den Burg B, Karsens J, Venema G, Kok J: Design of thermolabile bacteriophage repressor mutants by comparative molecular modeling. Nature Biotechnol 1997, 15:960-963.

31. Kankainen M, Paulin L, Tynkkynen S, von Ossowski I, Reunanen J, Partanen P, Satokari R, Vesterlund S, Hendrickx AP, Lebeer S, De Keersmaecker SC, Vanderleyden J, Hämäläinen T, Laukkanen S, Salovuori N, Ritari J, Alatalo E, Korpela R, Mattila-Sandholm T, Lassig A, Hatakka K, Kinnunen KT, Karjalainen H, Saxelin M, Laakso K, Surakka A, Palva A, Salusjärvi T, Auvinen P, de Vos WM: Comparative genomic analysis of Lactobacillus rhamnosus GG reveals pili containing a human- mucus binding protein. Proc Natl Acad Sci USA 2009, 106:17193-8.

32. Barrangou R, Fremaux C, Deveau H, Richards M, Boyaval P, Moineau S, Romero DA, Horvath P: CRISPR provides acquired resistance against viruses in prokaryotes. Science 2007, 315:1709-12.

33. Garneau JE, Dupuis ME, Villion M, Romero DA, Barrangou R, Boyaval $P$ Fremaux C, Horvath P, Magadán AH, Moineau S: The CRISPR/Cas bacterial immune system cleaves bacteriophage and plasmid DNA. Nature 2010, 468:67-71.

34. Horvath P, Barrangou R: CRISPR/Cas, the immune system of bacteria and archaea. Science 2010, 327:167-70.

35. Boot $\mathrm{H}$, Kolen CPAM, Pouwels PH: Interchange of the active and silent Sprotein genes of Lactobacillus acidophilus by inversion of the chromosomal slp segment. Mol Microbiol 196 21:799-809.

36. Åvall-Jskelinen S, Palva A: Lactobacillus surface layers and their applications. FEMS Microbiol Rev 2005, 29:511-529.

37. Konstantinov SR, Smidt H, De Vos WM, Bruijns SC, Singh SK, Valence F, Molle D, Lortal S, Altermann E, Klaenhammer TR, van Kooyk Y: S layer protein $A$ of Lactobacillus acidophilus NCFM regulates immature dendritic cell and T cell functions. Proc Natl Acad Sci USA 2008, 105:19474-478.

38. Daly C, Fitzgerald GF, Davis R: Biotechnology of lactic acid bacteria with special reference to bacteriophage resistance. Ant Leeuwenh 1996, 70:99-110.

39. Delves-Broughton J, Blackburn P, Evans RJ, Hugenholtz J: Applications of the bacteriocin, nisin. Ant Leeuwenh 1996, 69:193-202.

40. Machielsen R, Siezen RJ, van Hijum SA, van Hylckama Vlieg JE: Molecular description and industrial potential of Tn6098 conjugative transfer conferring alpha-galactoside metabolism in Lactococcus lactis. Appl Environ Microbiol 2011, 77:555-63.

41. Jore MM, Lundgren $M$, van Duijn E, Bultema JB, Westra ER, Waghmare SP, Wiedenheft B, Pul U, Wurm R, Wagner R, Beijer MR, Barendregt A, Zhou K, 
Snijders AP, Dickman MJ, Doudna JA, Boekema EJ, Heck AJ, van der Oost J, Brouns SJ: Structural basis for CRISPR RNA-guided DNA recognition by Cascade. Nature Struct Mol Biol 2011, 18:529-36.

42. Brouns SJ, Jore MM, Lundgren M, Westra ER, Slijkhuis RJ, Snijders AP, Dickman MJ, Makarova KS, Koonin EV, van der Oost J: Small CRISPR RNAs guide antiviral defense in prokaryotes. Science 2008, 321:960-4.

43. Van de Guchte M, Kok J, Venema G: Gene expression in Lactococcus lactis. FEMS Microbiol Rev 1992, 8:73-92.

44. Kuipers OP, De Ruyter PG, Kleerebezem M, de Vos WM: Controlled overproduction of proteins by lactic acid bacteria. Trends Biotechnol 1997, 15:135-40.

45. Mierau I, Kleerebezem M: 10 years of the nisin-controlled gene expression system [NICE] in Lactococcus lactis. Appl Microbiol Biotechnol 2005, 68:705-17.

46. De Ruyter PG, Kuipers OP, Meijer WC, De Vos WM: Food-grade controlled lysis of Lactococcus lactis for accelerated cheese ripening. Nature Biotechnol 1997, 15:976-9

47. Gasson MJ: Plasmid complements of Streptococcus lactis NCDO 712 and other lactic streptococci after protoplast-induced curing. J Bacteriol 1983, 154:1-9.

48. Chopin A, Chopin MC, Moillo-Batt A, Langella P: Two plasmid-determined restriction and modification systems in Streptococcus lactis. Plasmid 1984, 11:260-3.

49. Bolotin A, Mauger S, Malarme K, Ehrlich SD, Sorokin A: Low-redundancy sequencing of the entire Lactococcus lactis IL1403 genome. Ant Leeuwenh 1999, 76:27-76.

50. Bolotin A, Wincker P, Mauger S, Jaillon O, Malarme K, Weissenbach J, Ehrlich SD, Sorokin A: The complete genome sequence of the lactic acid bacterium Lactococcus lactis ssp. lactis IL1403. Genome Res 2001, 11:731-53

51. Wegmann U, O'Connell-Motherway M, Zomer A, Buist G, Shearman C, Canchaya C, Ventura M, Goesmann A, Gasson MJ, Kuipers OP, van Sinderen D, Kok J: Complete genome sequence of the prototype lactic acid bacterium Lactococcus lactis subsp. cremoris MG1363. J Bacteriol 2007, 189:3256-70

52. Linares DM, Kok J, Poolman B: Genome sequences of Lactococcus lactis MG1363 [revised] and NZ9000 and comparative physiological studies. J Bacteriol 2010, 192:5806-12.

53. Chapot-Chartier MP, Vinogradov E, Sadovskaya I, Andre G, Mistou MY, TrieuCuot P, Furlan S, Bidnenko E, Courtin P, Péchoux C, Hols P, Dufrêne YF, Kulakauskas S: Cell surface of Lactococcus lactis is covered by a protective polysaccharide pellicle. J Biol Chem 2010, 285:10464-71.

54. Kleerebezem M, Boekhorst J, van Kranenburg R, Molenaar D, Kuipers OP, Leer R, Tarchini R, Peters SA, Sandbrink HM, Fiers MW, Stiekema W, Lankhorst RM, Bron PA, Hoffer SM, Groot MN, Kerkhoven R, de Vries M, Ursing B, De Vos WM, Siezen RJ: Complete genome sequence of Lactobacillus plantarum WCFS1. Proc Natl Acad Sci USA 2003, 100:1990-5.

55. Vesa T, Pochart P, Marteau P: Pharmacokinetics of Lactobacillus plantarum NCIMB 8826, Lactobacillus fermentum KLD, and Lactococcus lactis MG 1363 in the human gastrointestinal tract. Aliment Pharmacol Ther 2000, 14(6):823-8

56. Grangette C, Nutten S, Palumbo E, Morath S, Hermann C, Dewulf J, Pot B, Hartung T, Hols P, Mercenier A: Enhanced antiinflammatory capacity of a Lactobacillus plantarum mutant synthesizing modified teichoic acids. Proc Natl Acad Sci U S A 2005, 102:10321-6.

57. Marco ML, de Vries MC, Wels M, Molenaar D, Mangell P, Ahrne S, de Vos WM, Vaughan EE, Kleerebezem M: Convergence in probiotic Lactobacillus gut-adaptive responses in humans and mice. ISME J 2010, 4:1481-4.

58. van Baarlen $\mathrm{P}$, Troost FJ, van Hemert $\mathrm{S}$, van der Meer $\mathrm{C}$, de Vos WM, de Groot PJ, Hooiveld GJ, Brummer RJ, Kleerebezem M: Differential NF-kappaB pathways induction by Lactobacillus plantarum in the duodenum of healthy humans correlating with immune tolerance. Proc Natl Acad Sci USA 2009, 106:2371-6.

59. Teusink B, Wiersma A, Molenaar D, Francke C, De Vos WM, Siezen RJ, Smid EJ: Analysis of growth of Lactobacillus plantarum WCFS1 on a complex medium using a genome-scale metabolic model. $J$ Biol Chem 2006, 281:40041-8

60. Hugenholtz J, Smid E: Functional genomics for food fermentation processes. Ann Rev Food Sci Technol 2010, 1.
61. O'Flaherty S, Klaenhammer TR: The impact of omic technologies on the study of food microbes. Ann Rev Food Sci Technol 2011, 2.

62. Wells $\mathrm{J}$ : Mucosal vaccination and therapy with genetically modified lactic acid bacteria. Ann Rev Food Sci Technol 2011, 2.

63. Altermann E, Russell WM, Azcarate-Peril MA, Barrangou R, Buck BL, McAuliffe O, Souther N, Dobson A, Duong T, Callanan M, Lick S, Hamrick A, Cano R, Klaenhammer TR: Complete genome sequence of the probiotic lactic acid bacterium Lactobacillus acidophilus NCFM. Proc Natl Acad Sci USA 2005, 102:3906-12.

64. Van de Guchte M, Penaud S, Grimaldi C, Barbe V, Bryson K, Nicolas P, Robert C, Oztas S, Mangenot S, Couloux A, Loux V, Dervyn R, Bossy R, Bolotin A, Batto JM, Walunas T, Gibrat JF, Bessières P, Weissenbach J, Ehrlich SD, Maguin E: The complete genome sequence of Lactobacillus bulgaricus reveals extensive and ongoing reductive evolution. Proc Natl Acad Sci USA 2006, 103:9274-9.

65. Bolotin A, Quinquis B, Renault P, Sorokin A, Ehrlich SD, Kulakauskas S, Lapidus A, Goltsman E, Mazur M, Pusch GD, Fonstein M, Overbeek R, Kyprides N, Purnelle B, Prozzi D, Ngui K, Masuy D, Hancy F, Burteau S, Boutry M, Delcour J, Goffeau A, Hols P: Complete sequence and comparative genome analysis of the dairy bacterium Streptococcus thermophilus. Nat Biotechnol 2004, 22:1554-8.

66. Claesson MJ, Li Y, Leahy S, Canchaya C, van Pijkeren JP, CerdeñoTárraga AM, Parkhill J, Flynn S, O'Sullivan GC, Collins JK, Higgins D, Shanahan F, Fitzgerald GF, van Sinderen D, OToole PW: Multireplicon genome architecture of Lactobacillus salivarius. Proc Natl Acad Sci USA 2006, 103:6718-23.

67. Mohamadzadeh M, Pfeiler EA, Brown JB, Zadeh M, Gramarossa M, Managlia E, Bere P, Sarraj B, Khan MW, Pakanati KC, Ansari MJ, O'Flaherty S, Barrett T, Klaenhammer TR: Regulation of induced colonic inflammation by Lactobacillus acidophilus deficient in lipoteichoic acid. Proc Natl Acad Sci USA 2011, 108(Suppl 1):4623-30.

68. van Baarlen $\mathrm{P}$, Troost F, van der Meer C, Hooiveld G, Boekschoten M, Brummer RJ, Kleerebezem M: Human mucosal in vivo transcriptome responses to three lactobacilli indicate how probiotics may modulate human cellular pathways. Proc Natl Acad Sci USA 2011, 108(Suppl 1):4562-9.

69. Corr SC, Li Y, Riedel CU, O'Toole PW, Hill C, Gahan CG: Bacteriocin production as a mechanism for the antiinfective activity of Lactobacillus salivarius UCC118. Proc Natl Acad Sci USA 2007, 104:7617-21.

70. Makarova K, Slesarev A, Wolf Y, Sorokin A, Mirkin B, Koonin E, Pavlov A, Pavlova N, Karamychev V, Polouchine N, Shakhova V, Grigoriev I, Lou Y, Rohksar D, Lucas S, Huang K, Goodstein DM, Hawkins T, Plengvidhya V, Welker D, Hughes J, Goh Y, Benson A, Baldwin K, Lee JH, Díaz-Muñiz I, Dosti B, Smeianov V, Wechter W, Barabote R, Lorca G, Altermann E, Barrangou R, Ganesan B, Xie Y, Rawsthorne H, Tamir D, Parker C, Breidt F, Broadbent J, Hutkins R, O'Sullivan D, Steele J, Unlu G, Saier M, Klaenhammer T, Richardson P, Kozyavkin S, Weimer B, Mills D: Comparative genomics of the lactic acid bacteria. Proc Natl Acad Sci USA 2006, 103:15611-6.

71. Pridmore RD, Berger B, Desiere F, Vilanova D, Barretto C, Pittet AC, Zwahlen MC, Rouvet M, Altermann E, Barrangou R, Mollet B, Mercenier A, Klaenhammer T, Arigoni F, Schell MA: Title The genome sequence of the probiotic intestinal bacterium Lactobacillus johnsonii NCC 533. Proc Natl Acad Sci USA 2004, 101:2512-7.

72. Boekhorst J, Siezen RJ, Zwahlen MC, Vilanova D, Pridmore RD, Mercenier A, Kleerebezem M, de Vos WM, Brüssow H, Desiere F: The complete genomes of Lactobacillus plantarum and Lactobacillus johnsonii reveal extensive differences in chromosome organization and gene content. Microbiology 2004, 150:3601-11.

73. Fontaine L, Boutry C, de Frahan MH, Delplace B, Fremaux C, Horvath P, Boyaval $\mathrm{P}$, Hols P: A novel pheromone quorum-sensing system controls the development of natural competence in Streptococcus thermophilus and Streptococcus salivarius. J Bacteriol 2010, 192:1444-54.

74. Kant R, Blom J, Palva A, Siezen RJ, de Vos WM: Comparative genomics of Lactobacillus. Microb Biotechnol 2011, 4:323-332.

75. Molenaar D, Bringel F, Schuren FH, de Vos WM, Siezen RJ, Kleerebezem M: Exploring Lactobacillus plantarum genome diversity by using microarrays. J Bacteriol 2005, 187:6119-27.

76. Pretzer G, Snel J, Molenaar D, Wiersma A, Bron PA, Lambert J, de Vos WM, van der Meer R, Smits MA, Kleerebezem M: Biodiversity-based 
identification and functional characterization of the mannose-specific adhesin of Lactobacillus plantarum. J Bacteriol 2005, 187:6128-36.

77. Bayjanov JR, Siezen RJ, van Hijum SA: PanCGHweb: a web tool for genotype calling in pangenome CGH data. Bioinformatics 2010, 26:1256-7.

78. Meijerink M, van Hemert S, Taverne N, Wels M, de Vos P, Bron PA, Savelkoul HF, van Bilsen J, Kleerebezem M, Wells JM: Identification of genetic loci in Lactobacillus plantarum that modulate the immune response of dendritic cells using comparative genome hybridization. PLoS One 2010, 5:e10632.

79. Human Microbiome Jumpstart Reference Strains Consortium, Nelson KE, Weinstock GM, Highlander SK, Worley KC, Creasy HH, Wortman JR, Rusch DB, Mitreva M, Sodergren E, Chinwalla AT, Feldgarden M, Gevers D, Haas BJ, Madupu R, Ward DV, Birren BW, Gibbs RA, Methe B, Petrosino JF, Strausberg RL, Sutton GG, White OR, Wilson RK, Durkin S, Giglio MG, Gujja S, Howarth C, Kodira CD, Kyrpides N, Mehta T, Muzny DM, Pearson M, Pepin K, Pati A, Qin X, Yandava C, Zeng Q, Zhang L, Berlin AM, Chen L, Hepburn TA, Johnson J, McCorrison J, Miller J, Minx P, Nusbaum C, Russ C, Sykes SM, Tomlinson CM, Young S, Warren WC, Badger J, Crabtree J, Markowitz VM, Orvis J, Cree A, Ferriera S, Fulton LL, Fulton RS, Gillis M, Hemphill LD, Joshi V, Kovar C, Torralba M, Wetterstrand KA, Abouellleil A, Wollam AM, Buhay CJ, Ding Y, Dugan S, FitzGerald MG, Holder M, Hostetler J, Clifton SW, Allen-Vercoe E, Earl AM, Farmer CN, Liolios K, Surette MG, Xu Q, Pohl C, Wilczek-Boney K, Zhu D: A catalog of reference genomes from the human microbiome. Science 2010, 328:994-9.

80. De Vos WM, Underwood HA, Davies FL: Plasmid DNA encoded bacteriophage resistance in Streptococcus cremoris SK11. FEMS Microbiol Lett 1984, 23:175-178.

81. De Vos WM: On the carrier state of bacteriophages in starter lactococci: An elementary explanation involving a bacteriophage-resistance plasmid. Neth Milk Dairy J 1989, 43:221-229.

82. Brooijmans R, de Vos WM, Hugenholtz J: Electron transport chains of lactic acid bacteria - walking on crutches is part of their lifestyle. F1000 Biol Rep 2009, 1:pii, 34.

83. Duwat P, Sourice S, Cesselin B, Lamberet G, Vido K, Gaudu P, Le Loir Y, Violet $F$, Loubière $P$, Gruss A: Respiration capacity of the fermenting bacterium Lactococcus lactis and its positive effects on growth and survival. J Bacteriol 2001, 183(15):4509-16.

84. Lechardeur D, Cesselin B, Fernandez A, Lamberet G, Garrigues C, Pedersen M, Gaudu P, Gruss A: Using heme as an energy boost for lactic acid bacteria. Curr Opin Biotechnol 2011, 22:143-9.

85. Pedersen MB, Garrigues C, Tuphile K, Brun C, Vido K, Bennedsen M, Møllgaard H, Gaudu P, Gruss A: Impact of aeration and heme-activated respiration on Lactococcus lactis gene expression: identification of a heme-responsive operon. J Bacteriol 2008, 190:4903-11.

86. Brooijmans RJ, Poolman B, Schuurman-Wolters GK, de Vos WM, Hugenholtz J: Generation of a membrane potential by Lactococcus lactis through aerobic electron transport. J Bacteriol 2007, 189:5203-9.

87. Brooijmans RJ, de Vos WM, Hugenholtz J: Lactobacillus plantarum WCFS1 electron transport chains. Appl Environ Microbiol 2009, 75:3580-5.

88. Pieterse B, Leer RJ, Schuren FH, van der Werf MJ: Unravelling the multiple effects of lactic acid stress on Lactobacillus plantarum by transcription profiling. Microbiology 2005, 151:3881-94.

89. Wels M, Overmars L, Francke C, Kleerebezem M, Siezen RJ: Reconstruction of the regulatory network of Lactobacillus plantarum WCFS1 on basis of correlated gene expression and conserved regulatory motifs. Microb Biotechnol 2011, 4:333-44.

90. Stevens MJ, Wiersma A, de Vos WM, Kuipers OP, Smid EJ, Molenaar D, Kleerebezem M: Improvement of Lactobacillus plantarum aerobic growth as directed by comprehensive transcriptome analysis. Appl Environ Microbiol 2008, 74:4776-8.

91. Sieuwerts S, Molenaar D, van Hijum SA, Beerthuyzen M, Stevens MJ, Janssen PW, Ingham CJ, de Bok FA, de Vos WM, van Hylckama Vlieg JE: Mixed-culture transcriptome analysis reveals the molecular basis of mixed-culture growth in Streptococcus thermophilus and Lactobacillus bulgaricus. Appl Environ Microbiol 2010, 76:7775-84.

92. Siewerts S: Analysis Of Molecular Interactions Between Yoghurt Bacteria By An Integrated Genomics Approach. PhD thesis Wageningen University, the Netherlands; 2009.

93. Randazzo CL, Torriani S, Akkermans AD, de Vos WM, Vaughan EE: Diversity, dynamics, and activity of bacterial communities during production of an artisanal Sicilian cheese as evaluated by $16 \mathrm{~S}$ rRNA analysis. Appl Environ Microbiol 2002, 68(4):1882-92.

94. Nam YD, Chang HW, Kim KH, Roh SW, Bae JW: Metatranscriptome analysis of lactic acid bacteria during kimchi fermentation with genome-probing microarrays. Int J Food Microbiol 2009, 130:140-6.

95. Weckx S, Allemeersch J, Van der Meulen R, Vrancken G, Huys G, Vandamme P, Van Hummelen P, De Vuyst L: Metatranscriptome analysis for insight into whole-ecosystem gene expression during spontaneous wheat and spelt sourdough fermentations. Appl Environ Microbiol 2011, 77:618-26

96. Siezen RJ, Wilson G, Todt T: Prokaryotic whole-transcriptome analysis: deep sequencing and tiling arrays. Microb Biotechnol 2010, 3:125-30.

97. Koskenniemi K, Laakso K, Koponen J, Kankainen M, Greco D, Auvinen P, Savijoki K, Nyman TA, Surakka A, Salusjärvi T, de Vos WM, Tynkkynen S, Kalkkinen N, Varmanen P: Proteomics and transcriptomics characterization of bile stress response in probiotic Lactobacillus rhamnosus GG. Mol Cell Prot 2011, 10, M110.002741.

98. Lebeer S, Claes I, Tytgat HLP, Verhoeven TLA, Marien E, von Ossowski I, Reunanen J, Palva A, De Vos WM, Vanderleyden J, De Keersmaecker SJC: Characterization of the pili of Lactobacillus rhamnosus GG for adhesion and immunomodulation in intestinal epithelial cells. Microbial Cell Fact 2011, 18.

99. Wegkamp A, Mars AE, Faijes M, Molenaar D, de Vos RC, Klaus SM, Hanson AD, de Vos WM, Smid EJ: Physiological responses to folate overproduction in Lactobacillus plantarum WCFS1. Microb Cell Fact 2010, 9:100-106.

100. Bron PA, Grangette C, Mercenier A, de Vos WM, Kleerebezem M: Identification of Lactobacillus plantarum genes that are induced in the gastrointestinal tract of mice. J Bacteriol 2004, 186:5721-9.

101. Bachmann H, de Wilt L, Kleerebezem M, van Hylckama Vlieg JE: Timeresolved genetic responses of Lactococcus lactis to a dairy environment. Environ Microbiol 2010, 12:1260-70.

102. Lambert JM, Bongers RS, Kleerebezem M: Cre-lox-based system for multiple gene deletions and selectable-marker removal in Lactobacillus plantarum. Appl Environ Microbiol 2007, 73:1126-35.

103. Bachmann H, Kruijswijk Z, Molenaar D, Kleerebezem M, van Hylckama Vlieg JE: A high-throughput cheese manufacturing model for effective cheese starter culture screening. J Dairy Sci 2009, 92:5868-82.

104. Van de Bunt B, Bron P, Sijtsma L, De Vos WM, Hugenholtz J: A new method to assess volatile metabolites in non-growing Lactococcus lactis cell suspensions with relevance for flavor formation in cheese., Submitted.

105. Machielsen R, van Alen-Boerrigter IJ, Koole LA, Bongers RS, Kleerebezem M, Van Hylckama Vlieg JE: Indigenous and environmental modulation of frequencies of mutation in Lactobacillus plantarum. Appl Environ Microbiol 2010, 76:1587-95.

106. de Visser JA, Akkermans AD, Hoekstra RF, de Vos WM: Insertion-sequencemediated mutations isolated during adaptation to growth and starvation in Lactococcus lactis. Genetics 2004, 168:1145-57.

107. Lapierre L, Mollet B, Germond JE: Regulation and adaptive evolution of lactose operon expression in Lactobacillus delbrueckii. J Bacteriol 2002, 184(4):928-35.

108. Ideker T, Dutkowski J, Hood L: Boosting signal-to-noise in complex biology: prior knowledge is power. Cell 2011, 44:860-3.

109. Teusink B, Wiersma A, Jacobs L, Notebaart RA, Smid EJ: Understanding the adaptive growth strategy of Lactobacillus plantarum by in silico optimisation. PLoS Comput. Biol 2009, 5:e1000410.

110. Smid EJ, Molenaar D, Hugenholtz J, De Vos WM, Teusink B: Functional ingredient production: application of global metabolic models. Curr Opin Biotechnol 2005, 16:190-197.

111. Teusink B, Smid EJ: Modelling strategies for the industrial exploitation of lactic acid bacteria. Nature Rev. Microbiol 2006, 4:46-56.

112. Lahtvee PJ, Adamberg K, Arike L, Nahku R, Aller K, Vilu R: Multi-omics approach to study the growth efficiency and amino acid metabolism in Lactococcus lactis at various specific growth rates. Microb Cell Fact 2011, 24:10-12.

113. Jia G, Stephanopoulos GN, Gunawan R: Parameter estimation of kinetic models from metabolic profiles: Two-phase dynamic decoupling method. Bioinformatics 2011.

114. Levering J, Musters MWJM, Bekker M, Bellomo D, Fiedler T, De Vos WM, Hugenholtz J, Kreikemeyer B, Kummer U, Teusink B: Role of phosphate in 
the central metabolism of two lactic acid bacteria - a comparative systems biology approach. Comp Syst Biol.

115. De Vos WM, Hugenholtz J: Engineering metabolic highways in Lactococci and other lactic acid bacteria. Trends Biotechnol 2004, 22:72-9.

116. Hols P, Kleerebezem M, Schanck AN, Ferain T, Hugenholtz J, Delcour J, de Vos WM: Conversion of Lactococcus lactis from homolactic to homoalanine fermentation through metabolic engineering. Nature Biotechnol 1999, 17:588-92.

117. Hugenholtz J, Kleerebezem M, Starrenburg M, Delcour J, De Vos WM, Hols P: Lactococcus lactis as a cell factory for high-level diacetyl production. Appl Environ Microbiol 2000, 66:4112-4.

118. Bongers RS, Hoefnagel MH, Kleerebezem M: High-level acetaldehyde production in Lactococcus lactis by metabolic engineering. Appl Environ Microbiol 2005, 71:1109-13.

119. Pastink MI: Comparative Functional Genomics of Amino Acid Metabolism of Lactic Acid Bacteria. PhD Thesis, Wageningen University, The Netherlands; 2009.

120. Martins dos Santos V, Müller M, de Vos WM: Systems biology of the gut: the interplay of food, microbiota and host at the mucosal interface. Curr Opin Biotechnol 2010, 21:539-50.

121. Vos P, Simons G, Siezen RJ, de Vos WM: Primary structure and organization of the gene for a procaryotic, cell envelope-located serine proteinase. J Biol Chem 1989, 264:13579-85.

122. Jensen PR, Hammer K: Artificial promoters for metabolic optimization. Biotechnol Bioeng 1998, 58:191-5.

123. Baker M: Synthetic genomes: The next step for the synthetic genome. Nature 2011, 473:403-408.

124. Santos F, Vera JL, van der Heijden R, Valdez G, de Vos WM, Sesma F, Hugenholtz J: The complete coenzyme B12 biosynthesis gene cluster of Lactobacillus reuteri CRL1098. Microbiology 2008, 154:81-93.

125. Goffin $P$, van de Bunt $B$, Giovane M, Leveau JH, Höppener-Ogawa S, Teusink B, Hugenholtz J: Understanding the physiology of Lactobacillus plantarum at zero growth. Mol Syst Biol 2010, 6:413.

126. Carroll J, Field D, O'Connor PM, Cotter PD, Coffey A, Hill C, Ross RP, O'Mahony J: Gene encoded antimicrobial peptides, a template for the design of novel anti-mycobacterial drugs. Bioeng Bugs 2010, 1(6):408-412.

127. Lebeer S, Vanderleyden J, De Keersmaecker SC: Host interactions of probiotic bacterial surface molecules: comparison with commensals and pathogens. Nature Rev Microbiol 2010, 8:171-84.

128. Robinson K, Chamberlain LM, Schofield KM, Wells JM, Le Page RW: Oral vaccination of mice against tetanus with recombinant Lactococcus lactis. Nature Biotechnol 1997, 15:653-7.

129. Mohamadzadeh M, Duong T, Sandwick SJ, Hoover T, Klaenhammer TR: Dendritic cell targeting of Bacillus anthracis protective antigen expressed by Lactobacillus acidophilus protects mice from lethal challenge. Proc Natl Acad Sci USA 2009, 106:4331-6.

130. Lopez de Felipe F, Kleerebezem M, de Vos WM, Hugenholtz J: Cofactor engineering: a novel approach to metabolic engineering in Lactococcus lactis by controlled expression of NADH oxidase. J Bacteriol 1998, 180:3804-8.

131. Skinner KA, Leathers TD: Bacterial contaminants of fuel ethanol production. J Ind Microbiol Biotechnol 2004, 31:401-8.

132. Liu S, Bischoff KM, Qureshi N, Hughes SR, Rich JO: Functional expression of the thiolase gene thl from Clostridium beijerinckii P260 in Lactococcus lactis and Lactobacillus buchneri. N Biotechnol 2010, 27:283-8.

133. Berezina OV, Zakharova NV, Brandt A, Yarotsky SV, Schwarz WH, Zverlov W: Reconstructing the clostridial $n$-butanol metabolic pathway in Lactobacillus brevis. Appl Microbiol Biotechnol 2010, 87:635-46.

134. de Vos WM: Advances in genomics for microbial food fermentations and safety. Curr Opin Biotechnol 2001, 12:493-98.

doi:10.1186/1475-2859-10-S1-S2

Cite this article as: de Vos: Systems solutions by lactic acid bacteria:

from paradigms to practice. Microbial Cell Factories 2011 10(Suppl 1):S2.

\section{Submit your next manuscript to BioMed Central and take full advantage of:}

- Convenient online submission

- Thorough peer review

- No space constraints or color figure charges

- Immediate publication on acceptance

- Inclusion in PubMed, CAS, Scopus and Google Scholar

- Research which is freely available for redistribution

Submit your manuscript at www.biomedcentral.com/submit
Biomed Central 